\title{
Article \\ A Study on the Effect of Construction and Demolition Waste (CDW) Plastic Fractions on the Moisture and Resistance to Indentation of Wood-Polymer Composites (WPC)
}

\author{
Ville Lahtela ${ }^{1, * \mathbb{C} \text { and Timo Kärki }}{ }^{2}$ \\ 1 SCI-MAT Research Platform, LUT University, P.O. Box 20, FI-53851 Lappeenranta, Finland \\ 2 Fiber Composite Laboratory, LUT University, P.O. Box 20, FI-53851 Lappeenranta, Finland; timo.karki@lut.fi \\ * Correspondence: ville.lahtela@lut.fi; Tel.: +358-40-705-1719
}

check for

updates

Citation: Lahtela, V.; Kärki, T. A Study on the Effect of Construction and Demolition Waste (CDW) Plastic Fractions on the Moisture and

Resistance to Indentation of

Wood-Polymer Composites (WPC). J. Compos. Sci. 2021, 5, 205. https:// doi.org/10.3390/jcs5080205

Academic Editors:

Francesco Tornabene and

Thanasis Triantafillou

Received: 3 June 2021

Accepted: 2 August 2021

Published: 3 August 2021

Publisher's Note: MDPI stays neutral with regard to jurisdictional claims in published maps and institutional affiliations.

Copyright: (c) 2021 by the authors. Licensee MDPI, Basel, Switzerland. This article is an open access article distributed under the terms and conditions of the Creative Commons Attribution (CC BY) license (https:// creativecommons.org/licenses/by/ $4.0 /)$.

\begin{abstract}
This paper investigated the moisture and strength properties of wood-polymer composites (WPC), which were made using three different recycled polymers using wood flour as filler. The recycled polymers were acrylonitrile butadiene styrene (ABS), polypropylene (PP), and polyethylene (PE), which were collected from among the construction and demolition waste (CDW) at a local waste management center. The commercial additives, such as a coupling agent and lubricant, were also included in the materials. Composite materials were manufactured with an agglomeration and an extrusion process. Water absorption and thickness swelling properties of composites, based on the recycled ABS and PE, were restricted compared to the recycled PP. The strength properties of WPC were determined with two methods, a traditional Brinell hardness and resistance to indentation. Using an ABS polymer as a matrix in the composite, the moisture and strength properties were improved. The recycled PP polymer caused these properties to be lowered, especially in the case of moisture properties. This study has shown that the method used can affect the measured value of certain properties. In addition, the sorting of recycled polymer fractions is desirable for the appearance of improved properties.
\end{abstract}

Keywords: construction and demolition waste; wood-polymer composite; water absorption; thickness swelling; Brinell hardness; indentation

\section{Introduction}

The construction and demolition sector plays an important role in the world and produces a high amount of waste. For example, in the area of the European Union (EU), construction and demolition waste (CDW) represent about one-third of all waste produced [1]. This includes various potential materials for recycling, such as plastic. The building and construction sector uses 19\% of all nonfiber plastics [2]. An organized recycling system for this material is widely missing. Only $31.1 \%$ of all collected plastics ended-up being recycled in Europe in 2016 [3]. However, there are several ways to increase the reuse of plastic materials, including sustainable practices and economic advantages. For example, the availability of existing material might be limited in the future and the reuse of plastic materials could decrease the total amount of waste produced. In addition, secondary raw material is assumed to be cheaper and can reduce the product's cost for material.

Wood-polymer composite (WPC) represents a strong target for plastic reuse. It is an environmentally friendly material, offering environmental advantages such as reduced dependence on non-renewable energy and material sources, as well as lower emission. WPC, consisting mainly of plastic polymer as a matrix and wood fiber as a filler, also contains a small amount of various additives. Most of WPC's components can be recycled, which further reduces the amount of generated waste and it is very sustainable solution for WPC product. The use of secondary raw materials minimizes the amount of waste disposed 
at landfills, which will reduce environmental emissions. The recycled raw materials might include variations in quality which leaves open questions concerning the functionality of these materials. Therefore, it must be evaluated within standardized tests. The applicable tests for WPC are, inter alia, the measurement of its hardness strength and moisture properties.

The hardness evaluation is easy and inexpensive to perform, and it is also a good indicator for other features such as tensile strength [4]. For example, the mechanical properties are positively correlated with density and hardness is also a fine indicator of density. In addition, improved surface hardness might reduce the need for surface coating [5]. Due to the different natures of the WPC matrix and filler, the moisture properties of materials are an essential feature for WPC evaluation. The general perception has been that the increased filler amount will also increase moisture behavior [6]. More specifically, particle size has been found to affect the moisture content of WPCs [7]. The water content of the composite also influences its hardness [8].

The aims of this study were to assess the hardness and moisture properties of WPC materials using three different recycled CDW plastic polymers and to compare the resulting properties with each other.

\section{Materials and Methods}

Three different recycled polymers, acrylonitrile butadiene styrene (ABS), polypropylene (PP), and polyethylene (PE), were used as the composite matrix in the experiments. The recycled polymers were collected from among the construction and demolition waste (CDW) at a local waste management center (Etelä-Karjalan Jätehuolto Oy, EKJH) located in SE Finland. The filler used in the composite was wood flour, which was prepared from a dried spruce species (Picea abies) and produced by hammer-milling and sieving (20 mesh). The coupling agent was Fusabond E226 (DuPont, Geneva, Switzerland), and Struktol TPW 113 (Struktol, Stow, OH, USA) was used as the lubricant. The components' amounts within the studied materials were as follows: recycled polymer (ABS, PP, or PE) $30 \%$, wood flour $64 \%$, coupling agent $3 \%$, and lubricant $3 \%$.

The recycled CDW polymers were processed with a two-step process after collection. The CDW polymers were crushed with a shredder apparatus (Untha LR 630) that was equipped with a $10-20 \mathrm{~mm}$ sieve, followed by treatment with a low-speed crusher (Shini SG-1635N) with a $5 \mathrm{~mm}$ sieve.

The studied materials were processed by two treatment processes. Firstly, the components were compounded with an agglomeration apparatus consisting of a turbomixer (Plasmec TRL 100/FV/W) and a cooler (Plasmec RFV-200). The agglomeration was performed at $200^{\circ} \mathrm{C}$ for 30-73 min into the electric current achieved $50 \mathrm{~A}$, and the correct grain size was defined by visual review. The compounded materials were then conveyed to the conical counter-rotating twin-screw extruder (CE 7.2 FE-Hans Weber Maschinenfabrik Gmbh, Kronach, Germany) that was equipped with decking board profile die, as depicted in Figure 1. During extrusion, the temperature of the barrel and tool varied between $167-181^{\circ} \mathrm{C}$ and $183-207^{\circ} \mathrm{C}$, respectively. The screw rotational rate was $14-15 \mathrm{rpm}$ and the feed rate was $15 \mathrm{~kg} / \mathrm{h}$ for all materials.

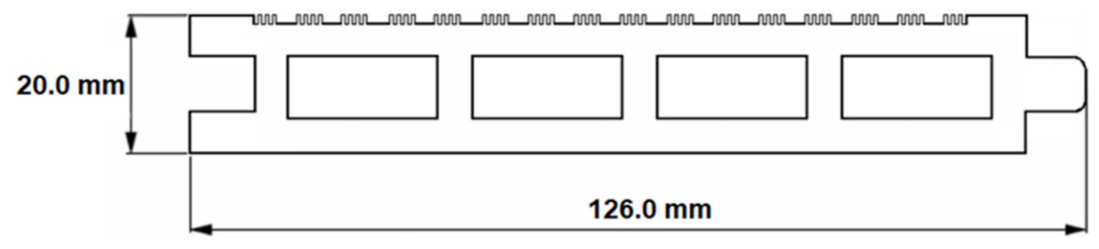

Figure 1. Schematic of the hollow-shape decking board profile.

The processed materials were characterized by using physical and mechanical standard testing methods. The samples for the tests were prepared by cutting items from the 
extruded profile by sliding table saw. The test specimens were conditioned at $23^{\circ} \mathrm{C}$ and $50 \%$ relative humidity until a constant mass was reached.

The water absorption (WA) and thickness swelling (TS) properties were determined by measuring the weights and dimensions of samples, based on the recommendations of standard EN 15534-1:2014 + A1:2017. The WA and TS results were calculated according to the following equations:

$$
\begin{gathered}
W A(\%)=\left(\left(m_{t}-m_{0}\right) / m_{0}\right) \times 100 \\
T S(\%)=\left(\left(t_{t}-t_{0}\right) / t_{0}\right) \times 100
\end{gathered}
$$

where $m_{0}, m_{t}$ and $t_{0}, t_{t}$ are the masses and thicknesses of the samples before and after immersion, respectively. The presented numbers are presented as the average values of the twenty square sizes samples, whose side length was $50 \mathrm{~mm}$ and thickness was the nominal thickness of the extruded profile.

The strength of the material was analyzed two times, based on two different methods (Brinell hardness and resistance to indentation). Brinell hardness was measured based on the standard EN 1534:2010 that is intended for the determination of resistance to indentation for wood flooring with a nominal value of a $1 \mathrm{kN}$ load, which should reach within $15 \pm 3 \mathrm{~s}$. The Brinell hardness $\left(H B_{1}\right)$ was calculated based on the following equation:

$$
H B_{1}=2 F /\left(g \times \pi \times D\left(D-\sqrt{ }\left(D^{2}-d^{2}\right)\right)\right)
$$

where $F$ is the load in newtons, $g$ is the acceleration of gravity in meters per second squared, $\pi$ is the "pi" factor, $D$ is the diameter of the ball in millimeters, and $d$ is the diameter of the residual indentation in millimeters, based on the average value of two measurements.

Additionally, the resistance to indentation was determined based on the standard EN 15534-1:2014 + A1:2017 based on the Brinell hardness, but differing in the load values and reach time. The preload was $20 \mathrm{~N}$ and additional load was increased until $2 \mathrm{kN}$ during $30 \pm 10 \mathrm{~s}$. Based on the resistance to indentation method, the hardness Brinell $\left(H B_{2}\right)$ and the rate of elastic recovery $(\operatorname{Rec})$ were calculated with the following equations and the results are presented in MPa and percentage (\%), respectively.

$$
H B_{2}=F /(\pi \times D \times l)
$$

where $F$ is the load in newtons, $D$ is the diameter of the indenter in millimeters, and $l$ is the depth of the indentation under a $2 \mathrm{kN}$ load in millimeters.

$$
\operatorname{Rec}=100 \times(1-(l r / l))
$$

where $l_{r}$ is the residual depth of the indentation after $24 \mathrm{~h}$, and $l$ is the depth of the indentations under a $2 \mathrm{kN}$ load. Both indentation depths were presented in millimeters.

The depth of the indentation under $2 \mathrm{kN}$ load can be accurately measured by the testing machine, but the residual depth of the indentation after $24 \mathrm{~h}$ is more problematic. In this study, the depth of indentation after $24 \mathrm{~h}$ was determined by the mathematical model, based on the diameter of the residual indentation, which was measured by the loop tool. The principle of the measurement of residual depth is presented in Figure 2.

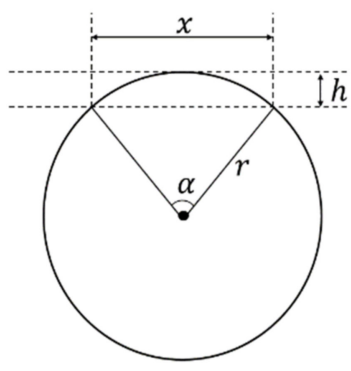

Figure 2. Layout for the measurement of the depth of the indentation after $24 \mathrm{~h}$. 
Based on the Figure 2, the measurement of depth was measured with the following formulas, according to the literature [9]:

$$
\begin{gathered}
h=r(1-\cos (\alpha / 2)) \\
\alpha \geq(\sin \alpha=(x-2) / r) \times 2
\end{gathered}
$$

where $h$ is the depth of indentation in millimeters, $r$ is the radius of the intender.

The presented strength numbers $\left(H B_{1}, H B_{2}\right)$ are presented as average values of the eight (8) square sizes samples whose side length was $75 \mathrm{~mm}$ and the thickness was the nominal thickness of the extruded profile.

\section{Results}

\subsection{Moisture Properties}

Figure 3 presents water absorption and thickness swelling properties. Water absorption was the lowest for CDW-ABS during the test period. After the test period (672 h), the CDW-ABS materials exhibited about $16 \%$ water absorption. The use of PP polymers as a matrix resulted in the highest water absorption (about $32 \%$ water absorption at the end of the test). Universally, the strength of water absorption was reduced after $336 \mathrm{~h}$. Before that, water absorption was stronger (especially at the beginning of the test). Thickness swelling was very high for the CDW-PP material, reaching over $13 \%$ of swelling after the test period. Correspondingly, the swelling of the CDW-PE material was low, reaching $2.5 \%$ of swelling at the end of the test. The standard deviation of moisture properties was quite minor with the ABS polymer, while it was higher with PP and PE polymers. The visually observed irregular surface of extruded material might cause wider deviation in the results, especially with the material of CDW-PE.

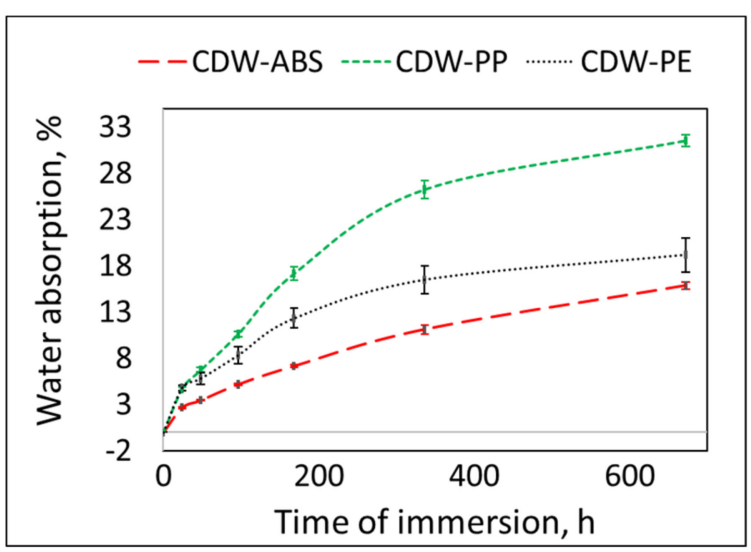

(a)

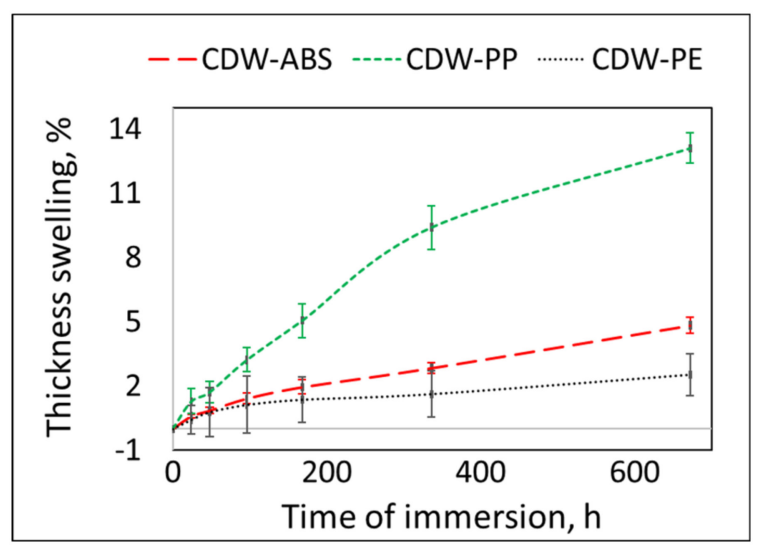

(b)

Figure 3. Water absorption (a) and thickness swelling (b) of the studied materials. The results consist of average values, with error bars describing the standard deviations.

\subsection{Strength Properties}

Table 1 presents the strength properties of the studied materials, measured by various methods. The achieved hardness results from various methods, which correlated quite well with each other. The CDW-ABS material had the best hardness property, while the CDW-PP had the weakest. Compared to the CDW-PP material, the use of recycled ABS polymers increased the Brinell hardness property by almost $50 \%$ and the resistance to indentation more than doubled. The hardness results $\left(H B_{1}\right.$ and $\left.H B_{2}\right)$ were similar between materials but the ratios between materials were slightly different. For example, the CDWABS was almost doubled compared to the CDW-PP with the Brinell hardness method $\left(H B_{1}\right)$, while the corresponding difference in the resistance to indentation method $\left(H B_{2}\right)$ was over tripled. 
Table 1. The strength properties (Brinell hardness $\left(H B_{1}\right)$, resistance to indentation $\left(H B_{2}\right)$, and recovery rate $(\operatorname{Rec})$ ) of the studied materials with standard deviations in parentheses.

\begin{tabular}{cccc}
\hline & HB $_{\mathbf{1}}$ & HB $_{\mathbf{2}}$ & Rec \\
\hline CDW-ABS & $7.71(0.26)$ & $36.64(14.76)$ & $13.33(10.72)$ \\
CDW-PP & $4.06(1.27)$ & $11.72(0.29)$ & NA \\
CDW-PE & $5.23(1.16)$ & $17.22(7.69)$ & $23.31(18.10)^{*}$ \\
\hline
\end{tabular}

*4 measurements.

The Brinell hardness method worked as expected for all materials, but the method of resistance to indentation, with stronger parameters, caused challenges in some cases. According to the method's instructions, the maintenance value $(2 \mathrm{kN})$ should be reached between 20 and $40 \mathrm{~s}$. Therefore, the test speed of the loading head must be applied by case-by-case, and varied between 3-9 mm/min. More exactly, the CDW-ABS test speed was $3 \mathrm{~mm} / \mathrm{min}$, CDW-PP was $9 \mathrm{~mm} / \mathrm{min}$, and CDW-PE was $5 \mathrm{~mm} / \mathrm{min}$. As was demonstrated in Figure 4, the maintenance force was problematic for the CDW-PP material since the intender with the $2 \mathrm{kN}$ force sank in the material, causing a decrease in the force. Hence, the fasteners of the intender were recaptured on the material, causing an increase in the force until the maintenance value was reached and, under the circumstances, the results of the CDW-PP were not completely valid. Additionally, the stabile $2 \mathrm{kN}$ maintenance force was difficult to reach immediately, as can be seen also in Figure 4.

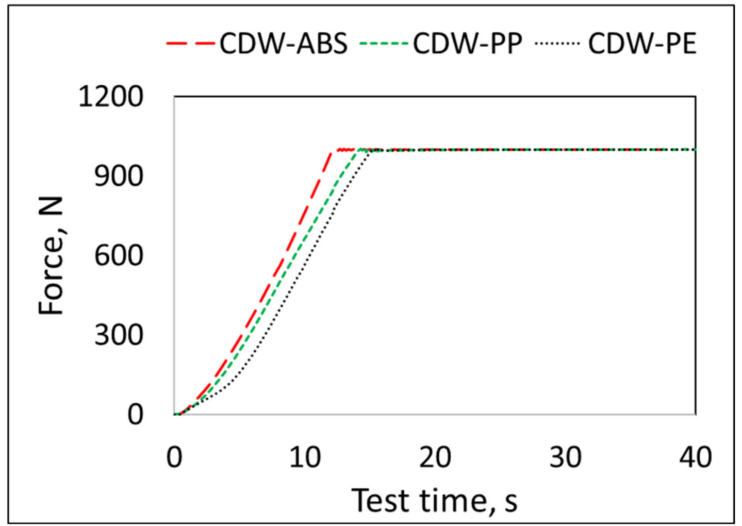

(a)

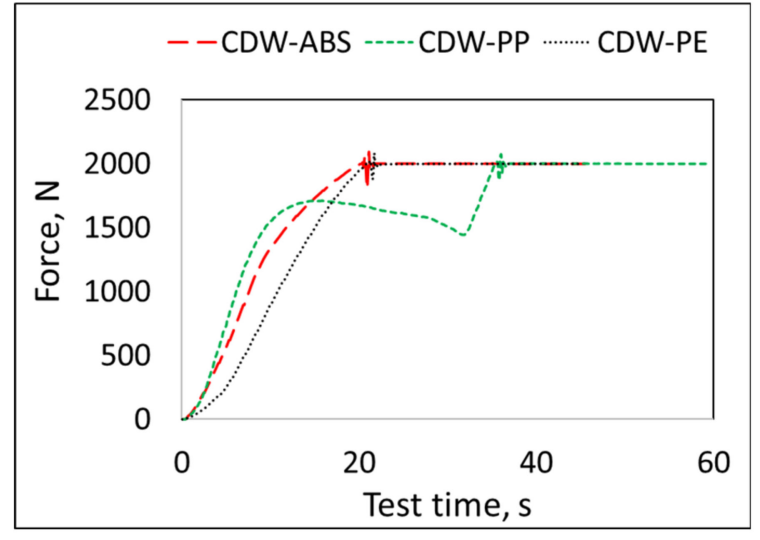

(b)

Figure 4. The strength curves of Brinell hardness $\left(H B_{1}\right)(\mathbf{a})$ and resistance to indentation $\left(H B_{2}\right)(\mathbf{b})$ with various materials.

\section{Discussion}

It is well known that a higher proportion of wood in a WPC structure increases WA and TS properties due to the presence of lumens, fine pores, and hydrogen bonding sites [10]. With the addition of $10 \%$ of wood flour, water absorption will increase by approximately $15 \%$ when the increased filler amount increases the motion of water molecules in their spaces and leads to an increase in WA [11]. As time passes, the water uptake of the composites will slow down [12]. The larger size particles increase the absorption in WPC since the larger particle sizes have larger water contact. The used particle sizes (20 mesh) reach the saturation point faster compared to the smaller particle sizes in manufactured composites [7]. The solutions for the improved moisture resistant properties are a correct coupling agent $[7,10]$, or an additive such as silane treatment that decreases water uptake with increasing concentration [12]. Filler modification, such as heat treatment, can also reduce water absorption due to its reduced hydrophilicity [13]. The swelling of materials has a connection with water absorption, but the polymer also has an influence on the moisture behavior. For example, ABS is polar component that might contribute to the greater interfacial interaction with the relatively highly polar wood material [14]. Therefore, the 
different amounts of polymers caused changes in the materials properties. The important factors for the swelling of WPCs are wood size and wood and coupling agent contents $[6,7]$. An increase by of $10 \%$ wood flour caused a $10 \%$ increase in thickness swelling [11]. The presence of a coupling agent in the composites enhances water resistance and its optimum level, depending on the size and content of the wood [7]. Even though the utilization of CDW polymers in the WPC is partly unfavorable, the CDW source might still include favorable raw materials for WPC since the moisture properties of WPC decreased with the addition of the CDW material [15].

While the increased wood content weakened the water resistance of WPC, the hardness value was increased with increasing wood content [4]. An addition of wood of up to 33\% was reported to be beneficial for improving hardness values [16]. Overall, wood content has an influence on the mechanical properties of composites and the optimum content varies between $40-50 \%$ [17]. The density also has an effect on the hardness, and it can vary according to wood material (due to the natural material's heterogeneity) and continue to affect the hardness of the composite [8]. The coupling agent also improves the strength properties of WPC, as it leads to less micro-voids in the interphase region [4]. Even though the increased amount of wood contributed to the hardness value, the source of the WPC material influences the hardness differently. For example, the CDW filler affects weakening of the hardness of WPC [15], while mineral additives increased the Brinell hardness values due to, inter alia, the increased interfacial adhesion between the components [16].

The solution for future hardness measuring could be the modified method from the managed standards, as described by, for example, Laine et al. [5]. In this case, the hardness test was carried out with increasing force until a nominal value of $1 \mathrm{kN}$. Since the diameter of the indentation is difficult to measure accurately, the depth of maximum indentation will be recorded and the hardness value will be determined based on the method of resistance to indentation, $\left(\mathrm{HB}_{2}\right)$.

Another step, in future, could be the improvement of the ratio amounts of the components. For example, a large amount of wood filler in the structure of the WPC might not be the most suitable, while a higher polymer amount would be desirable from a technical viewpoint. In addition, if recycled polymers were used in a WPC matrix, significant environmental benefits can be achieved, as Liikanen et al. [18] have addressed in their study.

\section{Conclusions}

The achieved results demonstrated that the method used represents a key factor in the comparison of composite materials. CDW includes various material fractions that can be applied for material reutilization, such as plastics. All of the studied polymers can be compounded by agglomeration and extrusion technologies into new WPC products. The moisture and strength properties of the studied materials were analyzed. ABS and PE polymers from the CDW source showed better performance values compared to the PP polymers. ABS polymers have especially excellent strength values. Due to their various material properties, all methods are not suitable for material evaluation and, therefore, it would be useful to modify the measuring method for WPC evaluation. The achieved results demonstrated that $\mathrm{CDW}$ fractions are reasonable to reuse as a material after sorting, based on the polymer composition. Using recycled polymers in WPC might be advantageous from various different perspectives, such as cost and environmental aspects.

Author Contributions: Conceptualization, V.L. and T.K.; methodology, V.L.; investigation, V.L.; resources, T.K.; writing-original draft preparation, V.L.; writing-review and editing, V.L. and T.K.; visualization, V.L.; supervision, T.K.; project administration, T.K.; funding acquisition, T.K. All authors have read and agreed to the published version of the manuscript.

Funding: This research received no external funding.

Acknowledgments: This study was supported by the LUT Fiber Composite Laboratory and LUT SCIMAT (Sustainable circularity of inorganic materials) research platform coordinated by Lappeenranta- 
Lahti University of Technology. The authors would like to thank these technical staff for their experimental assistance during the study.

Conflicts of Interest: The authors declare no conflict of interest.

\section{References}

1. Eurostat 2016 Waste Generation by Economic Activities and Households. Available online: https://ec.europa.eu/eurostat/ statistics-explained/index.php?title=File:Waste_generation_by_economic_activities_and_households,_2016_(\%25).png\& oldid=413554 (accessed on 17 December 2019).

2. Geyer, R.; Jambeck, J.R.; Law, K.L. Production, use, and fate of all plastics ever made. Sci. Adv. 2017, 3, 1-5. [CrossRef]

3. Plastic Europe, 2018 Plastics-The Facts 2018. Available online: https://www.plasticseurope.org/application/files/6315/4510/ 9658/Plastics_the_facts_2018_AF_web.pdf (accessed on 17 December 2019).

4. Kaymacki, A.; Ayrilmis, N. Investigation of correlation between Brinell hardness and tensile strength of wood plastic composites. Compos. Part B Eng. 2014, 58, 582-585.

5. Laine, K.; Rautkari, L.; Hughes, M. The effect of process parameters on the hardness of surface densified Scots pine solid wood. Eur. J. Wood Wood Prod. 2013, 71, 13-16. [CrossRef]

6. Adhikary, K.B.; Pang, S.; Staiger, M.P. Dimensional stability and mechanical behaviour of wood-plastic composites based on recycled and virgin high-density polyethylene (HDPE). Compos. Part B Eng. 2008, 39, 807-815. [CrossRef]

7. Kaboorani, A. Characterizing water sorption and diffusion properties of wood/plastic composites as a function of formulation design. Constr. Build. Mater. 2017, 136, 164-172. [CrossRef]

8. Garskaite, E.; Karlsson, O.; Stankeviciute, Z.; Kareiva, A.; Jones, D.; Sandberg, D. Surface hardness and flammability of $\mathrm{Na}_{2} \mathrm{SiO}_{3}$ and nano- $\mathrm{TiO}_{2}$ reinforced wood composites. RSC Adv. 2019, 9, 27973-27986. [CrossRef]

9. Råde, L.; Westergren, B. Mathematics Handbook for Science and Engineering, 5th ed.; Studentlitteratur: Lund, Sweden, 2008 ; p. 71.

10. Dalu, M.; Temiz, A.; Altuntaş, E.; Demirel, G.K.; Aslan, M. Characterization of tanalith E treated wood flour filled polylactic acid composites. Polym. Test. 2019, 76, 376-384. [CrossRef]

11. Beigloo, J.G.; Samariha, A. A study on composite from recycled high-density polyethylene and wood flour. J. Indian Acad. Wood Sci. 2019, 16, 9-14. [CrossRef]

12. Chen, Y.; Guo, X.; Peng, Y.; Cao, J. Water absorption and mold susceptibility of wood flour/polypropylene composites modified with silane-wax emulsions. Polym. Compos. 2019, 40, 141-148. [CrossRef]

13. Lafia-Araga, R.A.; Hassan, A.; Yahya, R.; Rahman, N.A.; Salleh, F.M. Water absorption behavior of heat-treated and red balau saw dust/LDPE composites: Its kinetics and effects on mechanical properties. J. Thermoplast. Compos. Mater. 2019, 32, 1408-1426. [CrossRef]

14. Rimdusit, S.; Atthakorn, D.; Damrongsakkul, S.; Saramas, S.; Tiptipakorn, S. Meachanical, Thermal, and water uptake characteristics of woodflour-filled polyvinyl chloride/acrylonitrile butadiene styrene blends. J. Appl. Polym. Sci. 2012, 124,943-950. [CrossRef]

15. Hyvärinen, M.; Ronkanen, M.; Kärki, T. The effect of the use of construction and demolition waste on the mechanical and moisture properties of a wood-plastic composite. Compos. Struct. 2019, 210, 321-326. [CrossRef]

16. Croioru, C.; Spirchez, C.; Cristea, D.; Lunguleasa, A.; Pop, M.A.; Bedo, T.; Roata, I.C.; Luca, M.A. Calcium carbonate and wood reinforced hybrid PVC composites. J. Appl. Polym. Sci. 2018, 135, 46317.

17. Mertens, O.; Gurr, J.; Krause, A. The utilization of thermochemical pulp fibers in WPC: A review. J. Appl. Polym. Sci. 2017, 134, 45161. [CrossRef]

18. Liikanen, M.; Grönman, K.; Deviatkin, I.; Havukainen, J.; Hyvärinen, M.; Kärki, T.; Varis, J.; Soukka, R.; Horttanainen, M. Construction and demolition waste as a raw material for wood polymer composites-Assessment of environmental impacts. J. Clean. Prod. 2019, 225, 716-727. [CrossRef] 